\title{
Keterampilan proses Sains pada Konsep Ekosistem Melalui Outdoor Learning dan Post to Post di SMA Negeri 1 Sungai Kakap
}

\author{
Kurnia Tiara Aulia ${ }^{1}$ ), Adi Pasah Kahar ${ }^{2)}$, Hanum Mukti Rahayu ${ }^{3)}$ \\ ${ }^{1,2,3)}$ Program Studi Pendidikan Biologi, FKIP, Universitas Muhammadiyah Pontianak \\ Pengiriman: 8 Desember 2017; Diterima: 14 Februari 2018; Publikasi: Maret 2018
}

\begin{abstract}
This research motivated by student's science proses skills which is low and one of them influenced by the teaching methods provided. A comparison of science process skills on different application of learning methods can determine appropriate methods for improving students process skills. This research purposes is, 1) to know the difference of students science process skills which is taught using outdoor learning and post to post, 2) to know which learning methods is the most affective to increase students science process skills in both of cognitive and psychomotor aspect. This research uses Quasi Experimental with Nonequivalent Control Group Design. The Sampling technique used purposice sampling. Data collection techniques uses measurement techniques for the cognitive science process skills and observation for the psychomotor science process skills. The gain value of reasearch result cognitive aspect in outdoor learning class is 35,39 , post to post is 31,41 and the test result of U-Mann whitney is 0,022 . The average value of psychomotor science process skills in outdoor learning class is 82,05 , post to post class is 85,82 and the test result of U-Mann whitney is 0,006 . The conclusion in this research there is a difference of cognitive science process skills between outdoor learning and post to post. the most effective of learning method for improving the cognitive science process skills is outdoor learning, and to improving the psychomotor science process skills is post to post.
\end{abstract}

\section{Keywords: cosystem, Science Process Skills, Outdoor Learning, Post To Post}

\begin{abstract}
ABSTRAK: Penelitian ini dilatarbelakangi oleh keterampilan proses sains siswa yang tergolong rendah, salah satunya dipengaruhi oleh metode pembelajaran yang diberikan oleh guru. Perbandingan keterampilan proses sains terhadap penerapan metode pembelajaran yang berbeda dapat menentukan metode yang tepat untuk meningkatkan keterampilan proses sains siswa. Tujuan penelitian ini, 1) mengetahui perbedaan ketarampilan proses sains siswa yang diajarkan menggunakan outdoor learning dan post to post, 2) mengetahui metode pembelajaran mana yang paling efektif untuk meningkatkan keterampilan proses sains siswa baik aspek kognitif maupun psikomorik. Bentuk penelitian ini menggunakan Quasi Experimental dengan rancangan Nonequivalent Control Group Design. Teknik sampling yang digunakan adalah purposive sampling. Teknik pengumpulan data yang digunakan adalah teknik pengukuran untuk keterampilan proses sains aspek kognitif dan observasi untuk keterampilan proses sains aspek psikomotorik. Hasil penelitian nilai gain KPS aspek kognitif di Kelas outdoor learning sebesar 35,39, kelas post to post sebesar 31,41 diperoleh hasil uji U-Mann Whitney yaitu 0,022. Sedangkan rata-rata nilai KPS aspek psikomotorik kelas outdoor learning sebesar 82,05, kelas post to post 85,82. Kesimpulan dalam penelitian ini adalah terdapat perbedaan KPS aspek kognitif antara outdoor learning dan post to post dan hasil uji UMann Whitney yaitu 0,006. Metode pembelajaran yang paling efektif untuk meningkatkan KPS aspek kognitif adalah outdoor learning sedangkan aspek psikomotorik yaitu metode post to post..
\end{abstract}

Kata Kunci: Ekosistem, Keterampilan proses sains, Outdoor Learning, Post To Post.

*Penulis Korespondensi:

Alamat surel: kurnia@gmail.com 


\section{PENDAHULUAN}

Biologi sebagai salah satu bidang dalam ilmu pengetahuan alam (IPA) menyediakan berbagai pengalaman belajar untuk memahami suatu konsep dan proses sains (BSNP, 2006:451). Pembelajaran biologi berkaitan dengan cara mencari tahu dan memahami tentang alam secara sistematis, sehingga biologi diharapkan dapat menjadi wahana bagi peserta didik untuk mempelajari diri sendiri dan alam sekitar (Trianto, 2007:99).

Materi ekosistem merupakan salah satu materi yang berkaitan dengan alam. Konsep ekosistem sendiri meliputi berbagai komponen seperti komponen biotik, interaksi antar organisme dan lingkungan, daur energi dan lain sebagainya yang dapat diamati secara langsung di lingkungan sekitar. Sitanggang (2015:157) menyatakan bahwa pembelajaran langsung dapat menggali potensi peserta didik dalam bertanya, beraktifitas, menemukan dan mengumpulkan data serta menganalisis dan membuat kesimpulan sendiri. Sehingga perlu dilakukannya proses pembelajaran langsung pada materi ekosistem agar siswa dapat memahami materi secara utuh berdasarkan objek yang diamatinya secara langsung.

Berdasarkan hasil wawancara yang dilakukan di SMAN 1 Sungai Kakap, dalam proses pembelajaran guru cenderung hanya menggunakan metode pembelajaran yang masih bersifat konvensional, seperti ceramah dan diskusi. Guru kurang memanfaatkan lingkungan sekolah untuk proses pembelajaran, padahal lingkungan sekolah sangat mendukung untuk proses pembelajaran khususnya pembelajaran ekosistem. Sehingga perlu dilakukannya perbaikan metode pembelajaran, salah satunya dengan menekankan proses pembelajaran secara langsung. Diantaranya yaitu pembelajaran outdoor learning dan post to post. kedua proses pembelajaran ini dilakukan di luar kelas. Husamah (2013:19) mengatakan bahwa pembelajaran outdoor learning merupakan metode pembelajaran sains dengan melakukan pertualangan dilingkungan sekitar. Pembelajaran post to post juga dilakukan diluar kelas yang dilengkapi dengan post untuk melakukan pengamatan (Istiani, 2015:72).

Kegiatan pembelajaran yang dilakukan secara langsung dapat meningkatkan keterampilan proses siswa, siswa akan mampu mengembangkan pemikirannya sendiri berdasarkan objek yang mereka amati. Kartimi (2013:76) menyatakan bahwa keterampilan proses sains merupakan keseluruhan keterampilan yang berupa aspek kognitif dan psikomotorik dalam melatih kemampuan mental, fisik dan sosial. Keterampilan proses sains aspek kognitif menekankankan kepada kemampuan kognitif (Astuti, 2016:341), sedangkan aspek psikomotorik lebih menekankan pada keterampilan siswa. Abungu (2014:341) menyatakan bahwa pengembangan keterampilan proses sains akan membantu siswa memperoleh pengalaman yang bersifat long term memory.

Keterampilan proses sains dimaksudkan untuk melatih dan mengembangkan keterampilan intelektual atau kemampuan berpikir siswa. Keterampilan proses sangat penting digunakan sebagai jembatan dalam menyampaikan pengetahuan/ informasi baru kepada siswa atau mengembangkan pengetahuan/informasi yang telah dimiliki oleh siswa. Keterampilan proses pada pembelajaran sains lebih menekankan pembentukan keterampilan untuk memperoleh pengetahuan dan mengkomunikasikan hasilnya (Buanarinda, 2014:9).

Berdasarkan hal tersebut sehingga perlu dilakukan penelitian dengan memanfaatkan metode outdoor learning dan post to post pada materi ekosistem untuk meningkatkan keterampilan proses sains siswa.

\section{METODE PENELITIAN}

Metode yang digunakan dalam penelitian ini adalah eksperimen dengan bentuk quasi experiment design. Jenis desain yang digunakan dalam penelitian yaitu 
nonequivalent control group design. Teknik pengambilan sampel yang dipilih adalah purposive sampling.Analisis data dalam penelitian ini diantaranya Pengolahan data hasil observasi KPS, pengolahan data pretest dan posttest, pengolahan perbedaan nilai keterampilan proses sains siswa dan menentukan metode yang paling efektif terhadap keterampilan proses sains menggunakan pembelajaran outdoor learning dan post to post.

\section{HASIL DAN PEMBAHASAN}

Perbedaan Keterampilan Proses Sains Aspek Kognitif

Hasil analisis lanjut uji U-Mann Whitney disajikan sebagi berikut :

Tabel 1 Uji U-Mann Whitney Nilai Gain kelas Outdoor Learning dan Post To Post

\begin{tabular}{ll}
\hline & \multicolumn{1}{c}{ NILAI } \\
\hline Mann-Whitney $U$ & 521.500 \\
Wilcoxon $W$ & 1.301 .500 \\
$Z$ & -2.295 \\
Asymp. Sig. (2-tailed) & 0.022 \\
\hline
\end{tabular}

Berdasarkan tabel diatas angka probabilitas yang diperoleh dari uji Mann Whitney yaitu $0,022<0,05$ maka Ha diterima yang berarti terdapat perbedaan keterampilan proses sains aspek kognitif antara kelas outdoor learning dengan kelas post to post.

Tabel 2 Rata-Rata Persentase Indikator KPS Aspek Kognitif

\begin{tabular}{ccc}
\hline \multirow{2}{*}{ Indikator } & \multicolumn{2}{c}{ Kelas } \\
\cline { 2 - 3 } & $\begin{array}{c}\text { Outdoor } \\
\text { Learning }\end{array}$ & $\begin{array}{c}\text { Post To } \\
\text { Post }\end{array}$ \\
\hline Menerapkan & & \\
Konsep & 74,73 & 74,95 \\
Klasifikasi & 86,17 & 83,97 \\
Prediksi & 80,25 & 78,20
\end{tabular}

\begin{tabular}{ccc} 
Interpretasi & 86,16 & 78,20 \\
Berhipotesis & 76,31 & 72,64 \\
\hline
\end{tabular}

Berdasartan tabel diatas terlihat perbedaan persentase KPS aspek kognitif antara outdoor learning dan post to post. Perbedaan hasil keterampilan proses sains aspek kognitif antara outdoor learning dan post to post disebabkan karena pada pembelajaran post to post siswa kurang mendapat kesempatan untuk mengembangan pemikiran mereka, mereka lebih terfokus kepada pertanyaan yang disediakan oleh guru pada tiap post. proses mengamati, mengklasifikasi, mempredikasi dan lainnya menjadi lebih terbatas. Selain itu tahapan pembelajaran outdoor learning mendukung keterampilan proses sains aspek kognitif seperti adanya kegiatan eksporasi melalui proses discovery (penemuan) dan inquiry (pemecahan masalah), adanya kegiatan meramalkan, pengamatan (observasi), adanya laporan dan mengkomunikasikan (Nisa, 2015:4). Dengan adanya tahapan-tahapan kegiatan seperti itu dalam outdoor learning dapat membuat siswa menjadi lebih mampu mengembangkan pemikiran mereka, sehingga dapat lebih meningkatkan KPS aspek kogntif siswa.

Perbedaan Keterampilan Proses Sains Aspek Psikomotorik

Tabel 3 Uji Mann Whitney U Hasil KPS Aspek Psikomotorik

\begin{tabular}{ll}
\hline & \multicolumn{1}{c}{ NILAI } \\
\hline Mann-Whitney $U$ & 483.000 \\
Wilcoxon $W$ & 1.224 .000 \\
$Z$ & -2.756 \\
Asymp. Sig. (2-tailed) & 0.006 \\
\hline
\end{tabular}

Berdasarkan Tabel diatas diperoleh angka probabilitas, yaitu $0,006<0,05$. Angka probabilitas uji Man Whitney lebih kecil dari 
0,05 maka Ha diterima yang berarti terdapat perbedaan keterampilan proses sains aspek psikomotorik antara kelas outdoor learning dengan kelas post to post.

Tabel 4 Rata-Rata Persentase Indikator KPS Aspek Psikomotorik

\begin{tabular}{ccc}
\hline \multirow{2}{*}{ Indikator } & \multicolumn{2}{c}{ Kelas } \\
\cline { 2 - 3 } & $\begin{array}{c}\text { Outdoor } \\
\text { Learning }\end{array}$ & $\begin{array}{c}\text { Post To } \\
\text { Post }\end{array}$ \\
\hline Observasi & 86,18 & 87,82 \\
Analisis Data & 81,9 & 84,26 \\
Berkomunikasi & 79,6 & 86,85 \\
\hline
\end{tabular}

Berdasarkan tabel diatas diketahui terdapat perbedaan keterampilan proses sains aspek psikomotorik dimana rata-rata persentase kelas post to post lebih tinggi dibandingkan kelas outdoor learning. Hal ini disebabkan karena proses pembelajaran yang diajarkan menggunakan post to post membuat siswa menjadi lebih terfokus dalam kegiatan lapangan. Dengan adanya pemberian waktu pada tiap post membuat siswa tidak memiliki waktu untuk bermain-main, siswa lebih fokus ke tujuan menyelesaikan permasalahan dalam setiap post yang sudah disediakan guru. Seperti yang dijelaskan oleh Istiani (2015:72) bahwa metode pembelajaran post to post digunakan untuk menggatasi kendala alokasi waktu yang kurang dan ketidakfokusan siswa dalam pembelajaran diluar kelas. Selain itu adanya penugasan pada tiap post ditujukan agar siswa lebih fokus, dan terlihat ketika proses pembelajaran berlangsung siswa menjadi lebih fokus dalam menyelesaikan permasalah dalam tiap post seperti pada kegiatan observasi, menganalisis data dan juga berkomunikasi.

Efektivitas Metode Pembelajaran Outdoor Learning dan Post To Post Terhadap Keterampilan Proses Sains
Tabel 5 Rekapitulasi Keefektivan Keterampilan Proses Sains Aspek Kognitif Kelas Outdoor Learning dan Post To Post.

\begin{tabular}{ccc}
\hline \multirow{2}{*}{ Kriteria } & \multicolumn{2}{c}{ Kelas } \\
\cline { 2 - 3 } & $\begin{array}{c}\text { Outdoor } \\
\text { Learning }\end{array}$ & $\begin{array}{c}\text { Post To } \\
\text { Post }\end{array}$ \\
\hline Rata-rata posttest & 80,65 & 76,92 \\
Rata-rata $N$-Gain & 0,64 & 0,57 \\
Ketuntasan & 94,73 & 82,05 \\
Klasikal(\%) & \\
\hline
\end{tabular}

$$
\text { Efektifitas }=\frac{0.64}{0.57}=1.12
$$

Nilai efektifitas yang diperoleh yaitu 1,12>1 maka metode pembelajaran outdoor learning lebih efektif terhadap keterampilan proses sains siswa aspek kognitif dibandingkan metode pembelajaran post to post.

Nisa (2015:4) menjelaskan ciri dari outdoor learning adalah adanya kegiatan eksplorasi melalui proses discovery dan inquiry, sementara itu objek yang dipelajari adalah lingkungan sekitar peserta didik. Ciri kedua adalah selalu ada kegiatan berupa peramalan (prediksi), pengamatan, dan penjelasan. Ciri ketiga adalah ada laporan untuk dikomunikasikan baik secara lisan, tulisan, gambar, foto, atau audiovisual. Ciri keempat kegiatan dirancang menyenangkan sehingga menimbulkan minat untuk belajar lebih lanjut.

Adanya proses discovery dan inquiry dalam proses pembelajaran outdoor learning menunjukan bahwa pada proses pembelajaran siswa dituntut untuk melakukan suatu penemuannya sendiri kemudian mencari dan menemukan sendiri jawaban dari permasalahan tersebut. Sehingga dapat meningkatkan hasil kognitif siswa.

Selain itu Ramadhani (2015:2) juga menyatakan bahwa selama proses 
pembelajaran siswa pada kelas outdoor learning dapat melakukan eksplorasi dengan bebas selama proses pembelajaran. Dengan membiarkan siswa melakukan eksplorasi dengan bebas dilingkungan, maka semakin banyak pula pengetahuan yang diperolehnya, hal ini tentunya akan berpengaruh positif terhadap kemampuan kognitif siswa.

Tabel 6 Rekapitulasi Keefektivan Keterampilan Proses Sains Aspek Psikomotorik Kelas Outdoor Learning dan Post To Post.

\begin{tabular}{ccc}
\hline \multirow{2}{*}{ Kriteria } & \multicolumn{2}{c}{ Kelas } \\
\cline { 2 - 3 } & $\begin{array}{c}\text { Outdoor } \\
\text { Learning }\end{array}$ & $\begin{array}{c}\text { Post To } \\
\text { Post }\end{array}$ \\
\hline Rata-rata nilai & 82,05 & 85,82 \\
$\begin{array}{c}\text { Ketercapaian } \\
\text { indikator (\%) }\end{array}$ & 92,1 & 100 \\
\hline
\end{tabular}

Berdasarkan tabel diatas diketahui bahwa ratarata nilai keterampilan proses sains aspek psikomotorik pada materi ekosistem yang diajarkan menggunakan metode pembelajaran post to post yaitu lebih tinggi dibandingkan KPS aspek psikomotorik yang diajarkan menggunakan metode outdoor learning. Hal ini menunjukan bahwa metode pembelajaran post to post lebih efektif meningkatkan KPS aspek psikomotorik siswa.

Istiani (2015:72) menyatakan bahwa metode pembelajaran post to post digunakan untuk menggatasi kendala alokasi waktu yang kurang dan ketidakfokusan siswa dalam pembelajaran diluar kelas. Selain itu adanya penugasan pada tiap post ditujukan agar siswa lebih fokus, dan terlihat ketika proses pembelajaran berlangsung siswa menjadi lebih fokus dalam menyelesaikan permasalah dalam tiap post.

Metode pembelajaran post to post juga mampu mendorong siswa menghubungkan apa yang diamatinya langsung di lapangan dengan pengetahuan yang didapatnya dari guru ataupun buku. Hal ini sejalan dengan Arihi (2012:77) bahwa dengan mendorong siswa menghubungkan antara pengetahuan dengan penerapannya di kehidupannya adalah untuk membekali siswa pengetahuan dan kemampuan untuk mendekatkan hal yang teoritis ke praktis. Sehingga dapat dikatakan bahwa hal ini dapat mengasah kemampuan psikomotorik siswa seperti kemampuan mengobservasi, menganalisis data dan berkomunikasi.

\section{KESIMPULAN DAN SARAN}

Berdasarkan hasil analisis data dan pembahasan yang telah dilakukan dalam penelitian ini diperoleh kesimpulan pada pengamatan interaksi tumbuhan dengan primata, diamati 2 jenis, yaitu Macaca fascicularis dan Presbytis melalophos primata yang berinteraksi dengan tumbuhan Ficus sp dan Quercus sp bergelantungan di dahan pohon, menggendong anak, dan makan. Berdasarkan hasil penelitian yang telah dilakukan dapat disimpulkan sebagai berikut terdapat perbedaan keterampilan proses sains yang diajarkan menggunakan metode outdoor learning dan post to post. metode pembelajaran outdoor learning lebih efektif dalam meningkatkan keterampilan proses sains aspek kognitif sedangkan metode pembelajaran post to post lebih efekif dalam meningkatkan keterampilan proses sains aspek psikomotorik.

\section{DAFTAR PUSTAKA}

Abungu,H.E., Okere,M.I.,\& Wachanga, S.M. 2014. The Effect of Science Skills Teaching Approach on Secondart School Students' Achievement in Chemistry in Nyando District, Kenya. Journal of Educational and Social Research.Vol 4(6):359-372.

Buanarinda,Tiara.P, \& Hidayah,R. 2014. Meningkatkan Keterampilan Proses Sains Melalui Model Pembelajaran Guided Inquiry pada Pembelajaran Konsep Asam Basa Kelas XI SMA 
Negeri Ploso Jombang. Unnesa Journal of Chemical Education. Vol 3(3):8-12.

Husamah.2013. Pembelajaran Luar Kelas Outdoor Learning. Jakarta:Prestasi Pustakaraya.

Iru, La. Arihi, La Ode Safiun. 2012. Analisis Penerapan Pendekatan, metode, Strategi, dan Model-Model Pembelajaran. Bantol: Multi Presindo.

Istiani,Rina.M, \& Retnoningsih,A. 2015. Pemanfaatan Lingkungan Sekolah Sebagai Sumber Belajar Menggunakan Metode Post To Post pada Materi Klasifikasi Makhluk Hidup. Unnes Journal of Biology Education. 4(1):7080 .

Kartimi, Gloria,Ria.Y., \& Ayani. 2013. Penerapan Pendekatan Keterampi lan Proses dalam Pengajaran Biologi untuk Mengetahui Hasil Belajar Siswa Pada Pokok Bahasan Ekosistem kelas VII di SMPN 1 Talun. Jurnal Scientiae Educatia. Vol 2(1): 73-85.

Nisa, Jakiatin. 2015. Outdoor Learning Sebagai metode Pembelajaran IPS dalam Menumbuhkan Karakter Peduli Lingkungan. Social Science Education Journal. Vol 2(1)..

Sitanggang \& Yulistiana. 2015. Peningkatan Hasil Belajar Ekosistem Melalui Penggunaan Laboratorium Alam. Jurnal Formatif. Vol 5(2): 156-167

Trianto. 2012. Model Pembelajaran Terpadu. Jakarta: PT Bumi Aksara. 